\title{
The phenomenological directness of perceptual experience
}

\author{
Boyd Millar
}

Published online: 26 September 2013

\begin{abstract}
When you have a perceptual experience of a given physical object that object seems to be immediately present to you in a way it never does when you consciously think about or imagine it. Many philosophers have claimed that naïve realism (the view that to perceive is to stand in a primitive relation of acquaintance to the world) can provide a satisfying account of this phenomenological directness of perceptual experience while the content view (the view that to perceive is to represent the world to be a certain way) cannot. I argue that this claim is false. Specifically, I maintain that the only acceptable naïve realist account of the relevant phenomenology is circular and that the content view can provide a similar account. In addition, I maintain that a certain specific variety of the content view provides a non-circular and thus more satisfactory account of this phenomenology. If so, then contrary to what is commonly assumed there are powerful phenomenological grounds for preferring the content view to naïve realism.
\end{abstract}

Keywords Perception - Phenomenology - Perceptual content - Naive realism · Content view

Perceptual experiences seem to put us in direct contact with physical things and their properties. For example, when you see a book in front of you the book itself seems to be present to you in a way it never does when you merely consciously think or imagine that the book is in front of you. As Strawson (1979, p. 47) puts it, "mature sensible experience (in general) presents itself as, in Kantian phrase, an immediate consciousness of the existence of things outside us". Any acceptable theory of perception must at least be compatible with this distinctive

B. Millar

University at Buffalo (SUNY), Buffalo, NY, USA 
phenomenology of perceptual experience-with its phenomenological directness. But, if a theory provides some satisfying account or explanation regarding why perceptual experiences possess this phenomenology, then this explanation is a significant benefit of the theory. Accordingly, if a given theory provides a more satisfying account of the phenomenological directness of perceptual experience than rival theories, then this fact constitutes a powerful reason to prefer that theory to its rivals.

Phenomenological considerations of just this sort have played a crucial role in the debate between the two presently dominant theories of perception: the relational view or naïve realism (the view that to perceive is to stand in a primitive relation of awareness or acquaintance to the world) and the representational or content view (the view that to perceive is to represent the world to be a certain way). ${ }^{1}$ Naiive realism is sometimes dismissed on the basis of facts concerning illusion and hallucination. For instance, when we hallucinate there is no object for us to be acquainted with; thus a naïve realist has to adopt the prima facie problematic view that hallucinatory experiences have a different structure than veridical or accurate experiences. ${ }^{2}$ Conversely, the content view has no such difficulties accommodating hallucination: a mental state or event can represent that there is an object in front of you even when this is false. However, a number of philosophers have recently argued that the phenomenological considerations in favour of naïve realism are sufficiently powerful that it ought to be preferred to the content view regardless of whatever disadvantages it may incur accounting for illusion and hallucination. Specifically, philosophers such as Crane (2006, pp. 139-141), Hellie (2007, pp. 266-269), Fish (2009, pp. 19-23), and Kennedy (2009, pp. 578-580), maintain that we should accept naïve realism because it can provide a satisfying account of the phenomenological directness of perceptual experience while the content view cannot. Phenomenological considerations of this sort have constituted perhaps the principal motivation for naïve realism in contemporary philosophy. And even philosophers who ultimately reject the view allow that naïve realism is uniquely well-suited to explain this distinctive phenomenology of perceptual experience. ${ }^{3}$ Consequently, whether naïve realism really can provide the kind of account of this phenomenology that the content view cannot is a critically important issue.

I maintain that the common assumption that naïve realism can provide a satisfying account of the phenomenological directness of perceptual experience while the content view cannot is mistaken. Instead, I claim that the account that naïve realism provides is no better than that which the content view provides-when it comes to explaining the relevant phenomenology, they are at least on equal

\footnotetext{
1 The "relational" versus "representational view" terminology is from Campbell (2002, Chap. 6). "Content view" is due to Brewer (2004, p. 68). "Naïve realism" has been used this way by many philosophers, including Martin (1997), Smith (2002), Fish (2009), and Kennedy (2009).

2 That is, naïve realists have to adopt disjunctivism. For an examination of this view see Byrne and Logue (2008).

3 For instance, Smith (2002, p. 69).
} 
footing. ${ }^{4}$ If correct, this conclusion would have significant consequences. Given that naïve realism has special difficulties accommodating illusion and hallucination, we need good reasons to prefer it to the content view; if naïve realism does not have an advantage explaining the phenomenological directness of perceptual experience, then a crucial source of support for the view is lost. But, in addition, I maintain that a particular variety of the content view in fact provides a more satisfying account of this phenomenology than naïve realism does. If so, then irrespective of the advantages that the content view has accommodating illusion and hallucination, and contrary to what is commonly assumed, there are powerful phenomenological grounds for preferring the content view to naïve realism.

First, in Sect. 1, I provide a more detailed description of naïve realism and the content view. In Sect. 2 I describe what I'm calling the phenomenological directness of perceptual experience, highlighting two distinct but closely connected aspects of that phenomenology. Then, in Sect. 3, I consider what I take to be the most plausible naïve realist accounts of the phenomenological directness of perceptual experience and argue that no such account is more satisfactory than that which can be provided by the content view. Specifically, I argue that the only acceptable naïve realist account of the relevant phenomenology is circular and that the content view can provide a very similar, and similarly circular, account. Finally, in Sect. 4 I outline a version of the content view that I maintain provides a non-circular and thus more satisfactory account of the relevant phenomenology.

\section{Naïve realism and the content view}

Naïve realism and the content view are competing theories of the structure of (at least certain kinds of) perceptual experience. An experience is a particular phenomenally conscious mental state or event-one which is like something for its subject. The phenomenal character or phenomenology of an experience is what the experience is like for the subject. We make judgments about phenomenology by relying on the special first-person access we have to our own experiences. Accordingly, different kinds of experiences can be distinguished from one another on the basis of their phenomenology.

Perceptual experiences are those experiences characteristic of the different sense modalities that at least ostensibly involve the presentation of physical things and their properties. ${ }^{5}$ Such experiences come in three types. An accurate or veridical perceptual experience is one where the things perceived have precisely the properties they are perceived to have. An illusory perceptual experience (or, more simply, an illusion) is one where the things perceived do not have all the properties they are perceived as having. And a hallucinatory perceptual experience

\footnotetext{
${ }^{4}$ Sturgeon (2000, pp. 12-15) draws the same conclusion, but his arguments are largely distinct from those I present in what follows.

${ }^{5}$ An important consequence of this use of the terminology is that there will be, for instance, visual experiences that are not visual perceptual experiences (more on this point below). See Siegel (2010, pp. 24-26).
} 
(a hallucination) is one where at least some of the things that from the subject's point of view seem to be perceived are not in fact perceived.

Naïve realism is not a theory of every type of perceptual experience; at most it is a theory of veridical experiences and illusions, and often it is restricted to veridical experiences alone. Conversely, the content view is at least potentially a theory of perceptual experiences in general. The disagreement between these two views, then, is in the first instance a disagreement about the structure of veridical perceptual experiences (from this point on, by "perceptual experience" I mean "veridical perceptual experience" unless I specify otherwise).

Naïve realism is the view that to have a perceptual experience is to stand in a primitive relation of awareness or acquaintance to some particular physical thing and its properties. As such, the naïve realist maintains that perceptual experiences are world-involving in a strong sense. For instance, suppose you visually perceive a book with a blue cover on a table immediately in front of you. According to the naïve realist, your perceptual experience consists in your standing in the relation of acquaintance to the particular book in front of you and the blueness of its cover. As the particular book and its blueness are constituents of this relational state of affairs, they are constituents of your perceptual experience. Moreover, that you have this experience entails that the particular book exists and that you are acquainted with it and its blueness.

A more specific characterization of naïve realism can be given in terms of the phenomenology of perceptual experience. That is, naïve realism can be characterized as the view that the phenomenology of a perceptual experience is constituted by the perceiver standing in a relation of acquaintance to particular physical things and their properties. ${ }^{6}$ As such, the naïve realist maintains that the phenomenology of a perceptual experience is constituted by particular physical things and their properties. For instance, when you visually perceive the book with the blue cover, the phenomenology of your perceptual experience consists in your standing in the relation of acquaintance to this particular book and the blueness of its cover. Consequently, this particular book and the blueness of its cover are constituents of the phenomenology of your perceptual experience.

Conversely, the content theorist says that when one perceives one is related to the world in virtue of being the subject of a mental state or event that represents the world to be a certain way. A representational mental state or event is one with a representational content; its content is the way the state or event represents the world as being. Paradigmatic examples include beliefs and desires. For instance, the content of my belief that the book is on the table is that the book is on the table. The content theorist says that my perceptual experience of the book on the table also has the content that the book is on the table. ${ }^{7}$

What it means for a mental state or event to have a representational content can be explained more precisely by appealing to a standard account of propositional

\footnotetext{
6 This is probably the most common way to characterize the view. See, for example, Campbell (2002, pp. 114-115), Hellie (2007, pp. 264-265), Fish (2009, pp. 14-15), and Nudds (2009, p. 335).

7 This is of course only part of the content of such an experience. Since perceptual contents are typically enormously complex the discussion will always be restricted to some specific aspect of a given content.
} 
attitudes. According to this account, regarding mental states such as beliefs and desires, the representational content of the state is a proposition and the attitude is a relation to that proposition. So, for instance, for me to believe that the book is on the table is for me to stand in the belief-relation to the proposition that the book is on the table; and for me to desire that the book is on the table is for me to stand in the desire-relation to that same proposition. Similarly, the content theorist claims that to have a perceptual experience of the book on the table is to stand in what we could call the perceptually-experiencing-relation to the proposition that the book is on the table. That is, the content theorist claims that perceptual experience is a unique kind of propositional attitude. ${ }^{8}$ Moreover, the content theorist claims that, just as a true belief is true in virtue of the fact that the proposition that constitutes its content is true, a veridical perceptual experience is veridical in virtue of the fact that the proposition that constitutes its content is true.

How a perceptual experience's representational content is related to its phenomenology is a controversial subject amongst content theorists. I will make the minimal assumption that for any given normal subject in a given environment, if any two of that subject's perceptual experiences possess different general representational contents then those experiences differ with regard to their phenomenology. ${ }^{9}$ In other words, I assume that the way your perceptual experience represents the world to be affects the phenomenology of your experience.

\section{Phenomenological directness}

Both the naïve realist and the content theorist can and should accept that perceptual experiences possess that feature I'm calling phenomenological directness. Very many philosophers who hold a wide variety of views regarding perception nonetheless agree that when you enjoy a perceptual experience, physical things and their properties seem to be directly present to you. ${ }^{10}$ This much can be taken for granted then: all our perceptual experiences possess a phenomenology of direct presence that none of our non-perceptual experiences possess.

\footnotetext{
8 Similar accounts of the content view are presented by Thau (2002, p. 74), Johnston (2004, pp. 176-177n.4), Byrne (2009, pp. 437-438), and Pautz (2009, p. 492; 2010, pp. 257-259). Siegel (2010, Chap. 2) presents a weaker version of the content view that she claims is consistent with naïve realism; she calls the view described above the "Strong Content View." For an argument in favour of preferring the stronger characterization, see Pautz (2009, Sect. 1).

9 This claim is restricted to general contents since a content theorist might claim that perceptual contents constitutively involve particular objects, times, or locations, and that it's possible for experiences with contents involving distinct particulars to be phenomenologically identical. See, for example, Speaks (2009).

${ }^{10}$ Hellie (2007, p. 266) produces a list of quotations of philosophers calling attention to this phenomenological feature; in addition to the quotation from Strawson reproduced above, the list includes quotations from Broad, McDowell, Sturgeon, and Levine. Some further examples: Husserl (1900/1970, p. 712), Searle (1983, pp. 45-46), Alston (1999, p. 182), Smith (2002, p. 43), Crane (2006, p. 134), Hellie (2007, p. 268), and Fish (2009, p. 4).
} 
However, there are two aspects to this distinctive phenomenology that are not always carefully distinguished. Consider Strawson's claim again that perceptual experience seems to be "an immediate consciousness of the existence of things outside us." He is making two closely connected phenomenological points here. First, Strawson is noting that the objects of perception seem to be presented immediately or directly to consciousness. Second, he is noting that the objects of perception are presented as "things outside us." In other words, the things that seem to be immediately present to us in perception seem to be distinct or separate from our consciousness. Strawson's statement thus highlights that there are in fact two different phenomenological features that make up the distinctive phenomenology of perceptual experience.

The distinction between these two features can be clarified by contrasting perceptual experience with other kinds of experience. First, it is typical to isolate the phenomenology of direct presence by contrasting perceptual experience with conscious thinking and imagining. ${ }^{11}$ For instance, compare visually perceiving that there is a book on the table in front of you with thinking or visualizing that there is a book on the table in front of you. When you see the book there seems to be some kind of direct contact between your mind and the book that is missing when you merely think that the book is in front of you or visualize seeing the book in front of you. That is, when you see it, the book itself seems to be simply revealed to your consciousness; the book itself does not seem to be present to your mind in this same way when you merely think about or visualize it. Modifying some terminology from Sturgeon (2000, Chap. 1) I will call this phenomenological feature of perceptual experience object-immediacy.

Second, we can isolate the phenomenological distinctness or separateness of the objects of perception by contrasting perceptual experience with brute sensation. For instance, consider the light and dark fuzz you experience when you close your eyes, or the coloured phosphenes you experience when you press on your closed eyes for a while. ${ }^{12}$ Such visual experiences possess object-immediacy. When you have an experience of some particular phosphene that phosphene itself seems to be directly present to your consciousness in a way that it would not were you to merely think about or visualize it sometime later. However, when you have a visual experience of a phosphene you do not seem to be presented with something that has an existence apart from that very experience of it; rather the phosphene seems to be merely some aspect of what it's like for you to have the experience. Conversely, when you visually perceive a physical thing like a book, you seem to be presented with something that is distinct from that very experience of it. I will call this phenomenological feature of perceptual experience object-distinctness.

Neither object-immediacy nor object-distinctness alone is unique to perceptual experience. As I've just said, brute sensations possess object-immediacy; and since

\footnotetext{
11 See, for example, Searle (1983, pp. 45-46), Alston (1999, p. 182), Sturgeon (2000, p. 27), Smith (2002, p. 43), Crane (2006, p. 139), and Hellie (2007, p. 268).

12 The visual experience you enjoy when your eyes are closed is given as an example of brute sensation by Smith (2002, p. 129) and Siegel (2010, p. 24). Phosphene experiences are discussed by Block (1996, p. 35), Smith (2002, pp. 129-130) and Siegel (2006, p. 372).
} 
the objects of any given episode of thinking or imagining seem to be distinct from the relevant conscious episode, such experiences possess object-distinctness. What distinguishes perceptual experience from non-perceptual kinds of experience, then, is the combination of these phenomenological features. When you have a perceptual experience it seems to be the case that something distinct from your consciousness is immediately present to your consciousness; the same is never true when you are merely thinking, imagining, or enjoying a brute sensation. (I will continue to use "phenomenological directness" to refer to the conjunction of these two phenomenological features, and "object-immediacy" and "object-distinctness" to refer to them individually).

\subsection{A digression concerning transparency}

Before moving on, it may be helpful to distinguish what I'm calling the phenomenological directness of perceptual experience from the purported transparency of perceptual experience. Briefly, the claim that perceptual experiences are transparent is the claim that when you turn your attention to any given experience, the only features you can become aware of seem to you to be features of ordinary physical things. It is sometimes suggested that transparency is a phenomenological feature of perceptual experience that any plausible theory of perception should account for. ${ }^{13}$ And Kennedy (2009) has recently suggested that there is a close connection between the phenomenological directness and transparency of perceptual experience. ${ }^{14}$ In my view, it does not follow from the fact that perceptual experiences possess phenomenological directness that they are transparent; and the claim that perceptual experiences are transparent lacks the powerful intuitive support possessed by the corresponding claim about phenomenological directness. ${ }^{15}$

Regarding the first point, transparency would only follow from phenomenological directness if we assumed that being able to turn one's attention to a feature that seems not to belong to any physical object would make it impossible for physical objects to seem to be immediately present in a perceptual experience. That is, we would have to assume that if when you engaged in first-person reflection on an experience you were able to turn your attention to features that seemed not to belong to any physical objects, then these features would necessarily "crowd out" physical objects or intervene between them and your mind. However, I see no reason to make this assumption.

Regarding the second point, there are any number of prima facie plausible examples that are inconsistent with the claim that perceptual experience is transparent. For instance: when I view a tilted penny I can turn my attention to a

\footnotetext{
13 For example, Martin (2002).

14 Kennedy (2009, p. 576) says that material objects are "at least apparently, the only things of which we are aware" in perceptual experience, and calls this phenomenological feature "manifest presence." Later, Kennedy (2009, pp. 578-579) treats the claim that perceptual experiences exhibit manifest presence as interchangeable with Alston's (1999, p. 182) claim that perceptual experiences seem to consist in a "direct, unmediated awareness" of physical objects.

15 Frey (2013) makes similar claims but characterizes the issues in slightly different terms.
} 
certain ellipticalness even though the penny does not seem to be elliptical; when I focus on any expanse of colour I can turn my attention to a certain flickering or fuzziness even though no physical thing seems to be flickering or fuzzy; when I take my glasses off I can turn my attention to a certain blurriness even though no physical thing seems to be blurry; when I have a double vision experience of my finger I can turn my attention to a certain doubleness even though my finger does not seem to have doubled; and as I adapt to a dark room I can turn my attention to a certain brightening even though my physical environment does not seem to be getting brighter (and the reverse is true for adapting to a bright room). ${ }^{16}$ On the basis of examples such as these, a number of philosophers have explicitly denied that perceptual experience is transparent. ${ }^{17}$ Conversely, it's difficult to see how someone could reasonably deny that perceptual experience is phenomenologically distinct from thought, imagination and brute sensation in the ways just described. ${ }^{18}$ Consequently, while I believe that the phenomenological directness of perceptual experience is a fact that any plausible theory of perception must address, I deny that the same can be said for the purported transparency of experience.

\section{Naïve realism and phenomenological directness}

Given that this phenomenological directness is what distinguishes perceptual experience from non-perceptual kinds of experience, if naïve realism can provide a satisfying account of this phenomenology while the content view cannot, then this fact would constitute a compelling reason to prefer naive realism to the content view. I assume that what it means for a theory of perception to provide an account of the phenomenological directness of perceptual experience is for the phenomenology to "fall out" of the theory. A theory of perception is a proposal about the structure of perceptual experience; if some feature of the proposed structure is sufficient for the relevant phenomenology, then the theory provides an account of why perceptual experience possesses this phenomenology. Accordingly, those philosophers who maintain that naïve realism can provide an account of the phenomenological directness of perceptual experience while the content view cannot maintain the following: first, that some element of the naïve realist's picture of perceptual experience is sufficient for this phenomenology; and second, that there is no comparable feature of the content theorist's picture that would enable the content theorist to provide an account of this phenomenology.

In particular, naïve realism is often assumed to have an advantage accounting for object-immediacy. In other words, it is often assumed that naïve realism captures

\footnotetext{
16 See Hellie (2006, Sect. 2.1) on the experience of tilted circular objects. See Hellie (2005, p. 493) on flickering experiences of colour. See Boghossian and Velleman (1989, p. 94), Crane (2006, pp. 130-131), Pace (2007), and Smith (2008) on blurry experiences. And see Boghossian and Velleman (1989, p. 94) on double vision experiences.

17 For example, Block (1996), Burge (2003), Crane (2006), Pace (2007), and Smith (2008).

18 For skepticism regarding the claim that perceptual experiences possess object-distinctness, see Spener (2012).
} 
the distinction between perceptual experience and thinking or imagining in a way that the content view cannot. Consequently, the central issue for present purposes is whether or not some feature of the naïve realist picture of perceptual experience is sufficient for object-immediacy. However, it's crucial to keep in mind that any proposed naïve realist account of object-immediacy will only be acceptable so long as it is compatible with the view providing an account of object-distinctness as well.

I maintain that naïve realism has no particular advantage over the content view with respect to accounting for object-immediacy. In defence of this conclusion, I will review those features of the naïve realist picture of perceptual experience that might plausibly be thought to be sufficient for object-immediacy. Since the naive realist claims that to have a perceptual experience is to stand in a relation of acquaintance to particular physical things and their properties, we may assume that a naïve realist account of object-immediacy will appeal to either the position of particular physical things in the structure of perceptual experience or the special nature of the relation of acquaintance. I will consider each of these proposals in turn. I hope to show that neither proposal enables the naïve realist to provide a more satisfactory account of object-immediacy than that which can be provided by the content view. ${ }^{19}$

\subsection{Physical things as constituents of perceptual experiences}

As we've seen, the naïve realist claims that perceptual experiences are worldinvolving in a strong sense. Some philosophers maintain that it's this feature of perceptual experience that suffices for object-immediacy and that the content view cannot account for object-immediacy because according to the content view perceptual experience is not world-involving in the same sense. For instance, Crane (2006, p. 140) maintains that naïve realism best captures the "apparent relationality" of perceptual experience because according to this view "perceiving an object is an essentially relational state, of which the object perceived is a constituent; so the perception is constitutively dependent on the object perceived". ${ }^{20}$ Conversely, he claims, the content view is not able to capture this apparent relationality since according to the content view a veridical perceptual experience and a hallucination are the same "fundamental kind" of experience, and thus being related to a particular object is not essential to having any particular perceptual experience.

\footnotetext{
19 It's worth noting that the naïve realist's claim to have an advantage over the content view with respect to capturing object-immediacy faces the following significant difficulty. Any naïve realist account of object-immediacy will appeal to some feature that veridical perceptual experiences possess and hallucinations lack; however, since hallucinations possess object-immediacy, we know that whatever feature the naïve realist appeals to is not necessary for object-immediacy. So, even if the naïve realist can provide an account of object-immediacy in veridical cases, we know that some alternative account of object-immediacy must be available - we know that some feature other than that which the naïve realist points to suffices for object-immediacy. However, since I believe that naïve realism does not have an advantage accounting for object-immediacy even when we restrict the discussion to veridical perceptual experience, I ignore this objection in what follows.
}

20 See also Martin (2004, p. 39) and Hellie (2007, p. 269). 
The difficulty with this proposal is that there are mental states and events that are world-involving in this strong sense but lack the phenomenological directness that perceptual experiences possess. For instance, according to a widespread view of singular thoughts, particular objects are constituents of the contents of such thoughts, and thus singular thoughts are constitutively dependent on particular objects. So, if I'm looking at a particular book on the table in front of me and think that it is blue, the particular book in front of me is a constituent of my thought; but this thought, unlike my perceptual experience, does not possess object-immediacy. Similarly, if Williamson (2000) is correct that propositional attitudes such as knowing and remembering are world-involving in a strong sense then such mental states constitute a counterexample to the present proposal: while facts about the world are arguably constituents of such attitudes, you can know or remember something without the relevant fact seeming to be immediately present to you. Consequently, for a mental state or event to be world-involving in the sense at issue is not sufficient for it to possess object-immediacy.

Alternatively, a naïve realist who maintains that the phenomenology of a perceptual experience is constituted by the perceiver standing in a relation of acquaintance to particular physical things and their properties could claim that the fact that physical things are constituents of an experience's phenomenology suffices for object-immediacy. That is, such a naïve realist could maintain that the objects of perception seem to be immediately present to the perceiver because such objects are constituents of the phenomenology of the experience and the phenomenology of an experience is something that necessarily seems to be immediately present to the subject of the experience. For instance, Langsam (1997, pp. 53-54) defines naïve realism as the view that particular aspects of the phenomenal character of an experience are properties of material objects and maintains that this view best captures how perceptual experience presents itself to commonsense reflection. ${ }^{21} \mathrm{~A}$ naïve realist defending this proposal could claim that, conversely, the content view cannot capture the way in which perceived objects seem to be immediately present to the perceiver precisely because the view denies that physical things are constituents of the phenomenology of perceptual experiences.

The difficulty with this proposal is that it appears to be incompatible with the naïve realist providing an account of object-distinctness. According to the present proposal, when I have an experience of the book on the table the book is part of the phenomenology my visual experience. The same is also true of my experience of a phosphene. But, unlike the phosphene, the book seems to be something more than just some aspect of the phenomenology of my experience; the book seems to have an existence distinct from my experience of it. The difficulty, then, is that if the book is a constituent of the phenomenology of my experience it's not clear what feature of my experience could suffice for the fact that the book seems to me to be not merely a constituent of the phenomenology of my experience. To account for this difference, the naïve realist would have to point to some property of the book that I am perceptually acquainted with. But, while the suggestion that we can be

$\overline{21}$ Kennedy (2009, p. 580) makes a similar claim. 
perceptually acquainted with properties of mind-independent objects such as shape, colour, position and the like is relatively straightforward, an object's property of being mind-independent is not the sort of property that one could be perceptually acquainted with. The difficulty is that mind-independence is a counterfactual property: the book I am presently perceiving, for instance, exists independently of my experience in that it would exist if I weren't perceiving it. And while I can judge or otherwise represent that the book has counterfactual properties of this sort, I can only do so on the basis of my perceptual acquaintance with other properties the book instantiates (that is, my mental connection to the book's counterfactual properties won't have the kind of immediacy and directness that perceptual acquaintance is supposed to involve). ${ }^{22}$ Consequently, the present proposal leaves unexplained why the book unlike the phosphene seems to me to exist independently of my experience. Therefore, even if this naïve realist proposal could provide an account of object-immediacy it would not be able to provide an account of objectdistinctness and as such it can't provide an account of the phenomenological directness of perceptual experience.

\subsection{The relation of acquaintance}

Assuming that a naïve realist can't provide an account of object-immediacy by appealing to the position of particular physical things in the structure of perceptual experience, the remaining alternative is to appeal to the relation of acquaintance. The naïve realist understands perceptual acquaintance to be a primitive, nonrepresentational mental relation that perceivers stand into particular physical things and their properties. One might think, then, that the naïve realist has an advantage over the content theorist because acquaintance is understood to be a more basic mental relation than representation. We know that enjoying a mental state or event that represents some particular physical thing to be a certain way is not sufficient for that thing seeming to be immediately present to the subject of that state or event. Accordingly, one might suggest that perceiving involves a more basic, nonrepresentational mental relation to physical things and that standing in this more basic relation to some particular physical thing is sufficient for object-immediacy. For instance, Sturgeon characterizes the naïve realist's reasoning along just these lines. "The idea," he says, "is that brute contact [or acquaintance] makes it for the subject as if a public object and its features are directly before the mind" (2000, p. 12).

The difficulty with this proposal is that there are primitive, non-representational mental relations that a subject can stand into physical things and their properties that are not sufficient for object-immediacy, and thus a naïve realist who appeals to the account at issue must distinguish perceptual acquaintance from such relations; however, there does not appear to be any way to distinguish perceptual acquaintance from other primitive, non-representational mental relations without appealing to

\footnotetext{
22 For an example of a naïve realist who makes the assumption that one cannot be perceptually acquainted with an object's counterfactual properties explicit, see Campbell (2002, pp. 137-145).
} 
object-immediacy. For instance, according to a standard view of acquaintance, you can be acquainted with some object in virtue of being connected to it through perception, memory, or a chain of communication. ${ }^{23}$ According to this understanding of acquaintance, I can be acquainted with some particular book even though I do not presently perceive it and it does not seem to be immediately present to my consciousness. This sort of acquaintance, then, is a primitive, non-representational mental relation that is not sufficient for object-immediacy.

Clearly the sort of acquaintance that the naïve realist has in mind is much more limited than the relation of acquaintance as it is often understood. However, because the kind of specifically perceptual acquaintance that the naïve realist has in mind is understood to be a primitive relation, there is no way to identify or specify this relation except to specify the situations in which a subject stands in this relation to something; and there is no way to specify the relevant situations without appealing to the phenomenological directness of perceptual experience. For example, Fish (2009, p. 14) explains what he means by 'acquaintance' as follows: “'acquaintance' names an irreducible mental relation that the subject can only stand in to objects that exist and features that are instantiated in the part of the environment at which the subject is looking". However, this explanation is inadequate as it stands since I might stand in some irreducible mental relation (e.g., acquaintance as often understood) to some physical object that occupies space in that part of the environment I am looking at and yet I might not be acquainted with it in the sense that Fish is trying to capture. After all, some other object might occlude my view of the relevant object, or it might be too small to be distinguishable by my weak eyes, or I might simply not notice it because my attention is focused elsewhere. Consequently, a naïve realist would at least have to add to Fish's explanation that a subject is acquainted with a physical object (or its features) in the relevant sense only when the subject is looking at the object, the object is close enough and large enough to be distinguishable, and the subject is attending to it - and no doubt additional restrictions would need to be added. ${ }^{24}$

Ultimately, the only way for the naïve realist to specify the relation of acquaintance adequately would be to continue adding restrictions of the sort just described until it is established that a subject is acquainted with a physical object only in cases where she has a conscious experience of that object that possesses phenomenological directness. The naïve realist simply has no grasp of what distinguishes perceptual acquaintance from other primitive, non-representational mental relations other than that it is the relation that a subject stands in to a physical object only when the subject's experience of that object has the right kind of phenomenology. In other words, the naïve realist can only identify this nonrepresentational mental relation as that kind of acquaintance that suffices for objectimmediacy.

The naïve realist is thus in the following position: she can point to a feature of the structure of perceptual experience that is sufficient for object-immediacy, but that

\footnotetext{
23 See, for example, Jeshion (2010, p. 109).

${ }^{24}$ Fish (2009, pp. 54-75) discusses these complications in some detail.
} 
feature can't be specified without appealing to the very phenomenology at issue. As such, the only plausible account naïve realism can provide of why perceptual experiences possess object-immediacy is circular. ${ }^{25}$

The fact that the only account naïve realism can provide of object-immediacy is circular is not a reason to reject the view. After all, it may well be that no theory of perception can provide a non-circular account of the relevant phenomenology. However, the question at issue is whether naïve realism can provide a more satisfactory account of object-immediacy than the content view can; and with respect to this question, the fact that the only account naïve realism can provide is circular is a serious problem. In particular, the problem is that the content view can provide a very similar account of object-immediacy. Remember that according to the content view perceptual experience is a propositional attitude: to have a perceptual experience of the book on the table is to stand in the perceptuallyexperiencing-relation to the proposition that the book is on the table. The content theorist will claim that the attitude involved in perceptual experience is distinct from attitudes like belief and desire; and when it comes to explaining what distinguishes the perceptually-experiencing-relation from the belief-relation or the desire-relation, the content theorist can say that it's the kind of attitude that a subject bears to a content only when he has a conscious experience possessing phenomenological directness. That is, the content theorist can identify the relevant attitude as that which suffices for object-immediacy. Thus some specific feature of the content theorist's proposed structure of perceptual experience is sufficient for objectimmediacy; but, admittedly, that feature can't be specified without appealing to the very phenomenology at issue. ${ }^{26}$

Ultimately, then, while naïve realism can provide an account of objectimmediacy by appealing to the special kind of acquaintance that perceivers have with physical things and their properties, this account is no more satisfactory than that which the content view can provide. The only plausible account naïve realism can provide of why perceptual experiences possess object-immediacy is circular, and a similarly circular account can be provided by the content view. Thus, contrary to what is typically assumed, naïve realists do not have an advantage with respect to explaining the phenomenological directness of perceptual experience.

\section{The content view and phenomenological directness}

Since the only plausible naïve realist account of the phenomenological directness of perceptual experience is circular, if some particular version of the content view can provide a plausible account that is not circular, then this account will be more satisfying than the naïve realist account. And if some particular version of the content view can provide a more satisfying account of this phenomenology than

\footnotetext{
25 Sturgeon (2000, pp. 13-14) makes the same point.

26 Chalmers (2004), Pautz (2007, p. 519) and Schellenberg (2011) defend accounts of this sort. Brewer (2011, p. 56) and Frey (2013, p. 82) complain that such accounts of object-immediacy are uninformative, but the present point is just that they are no less informative than naïve realist accounts.
} 
naïve realism can, then this fact would constitute a powerful reason to prefer that version of the content view to naïve realism. In this section I will outline a version of the content view that provides a plausible, non-circular account of the relevant phenomenology. ${ }^{27}$

Once again, the content view is often assumed to have a particular difficulty accounting for object-immediacy. We've just seen that a defender of the content view can claim that the perceptually-experiencing-relation is a special attitude that suffices for object-immediacy; but as an account of object-immediacy such a claim is circular. However, the content theorist has another option: she can provide an account of object-immediacy by appealing to the special nature of the representational contents that perceptual experiences involve. If the relevant representational contents can be specified without appealing to object-immediacy, then the content theorist can provide a non-circular account of object-immediacy.

The most promising approach, I believe, would be to appeal to the representation of the causal relation between the object of perception and the perceiver. Searle's (1983, Chap. 2) proposal regarding the content of perceptual experiences is a wellknown example of such a view. Searle claims that when you have a visual perceptual experience of a particular object in a particular location your visual experience represents that an object's being in a certain location is causing that very experience. For example, Searle (1983, p. 48) claims that when you have a visual experience of a particular yellow station wagon, the content of your experience is "that there is a yellow station wagon there and that there is a yellow station wagon there is causing this visual experience".

Searle (1983, p. 124n; 1991, p. 184) maintains that his proposal regarding perceptual content accounts for the phenomenological difference between visual perceptual experience and other kinds of experience, in particular visualization. However, while his view accounts for the phenomenological difference between perceptual experience and imagination, it can't provide an account of the phenomenological difference between perceptual experience and conscious thought. The difficulty is that a thought about a particular object can represent that the relevant object is causing that very thought, but such a thought still lacks objectimmediacy. For instance, when I notice the book on the table I can consciously think that there is a book on the table and that there is a book on the table is causing this very thought; but this thought will not seem to make the book itself present to me in the way that my visual experience does. Consequently, representing the object of an experience to be causing that very experience is not sufficient for objectimmediacy.

However, because the way in which physical things are causally related to perceptual experiences is distinct from the way in which they are causally related to every other kind of experience, it should be possible to improve on Searle's proposal. There are two unique features that are particularly important for present purposes. First, when there is a causal connection between a conscious thought about (or an episode of imagining) a particular physical object and that object, that

\footnotetext{
27 The following account will be brief. I motivate the view at greater length in Millar (forthcoming).
} 
causal connection always involves the mediation of some distinct experience. For instance, the causal chain connecting my conscious thought about the book on the table to the book always involves some distinct conscious experience-before I can have my conscious thought about the book I first have to perceive the book itself, or hear someone talk about the book, or something of the sort. Conversely, the causal connection between a perceptual experience of a given object and that object never involves the mediation of some distinct experience-I never, for instance, have a conscious thought of the book that then generates a visual experience of the book.

Second, a perceptual experience of a given object is only ever caused automatically (in the sense that the experience could not have been precipitated and cannot be terminated by the exercise of the subject's will) by a causal link to the (approximately) present state of that object. ${ }^{28}$ For example, I only ever have a visual experience of the book on the table when light that it has just now reflected impacts my retinas, and the resulting experience is not something I can voluntarily put an end to so long as this causal connection persists. Conversely, a conscious thought about (or episode of imagining) some particular physical object is typically under the voluntary control of the subject and does not require a causal link between that thought and the present state of the object. For instance, when I see that the book is on the table and then close my eyes I am still able to consciously think that the book is on the table as a result of the causal connection between that thought and the state the book was in a few seconds ago. And even when there is a causal connection between the present state of the book and my conscious thought about it, that thought is something that I could have brought about at will and can put an end to voluntarily (for instance, by deciding to think about something more interesting).

When an experience is caused by some physical thing such that, first, the causal connection between them does not involve the mediation of some distinct experience and, second, the experience is generated automatically by a causal link to the present state of the physical thing, I will say that the experience directly causally depends on that physical thing. So, for instance, my visual experience of the book on the table directly causally depends on the book, but my conscious thought about the book does not.

This point about the special nature of the causal relation between a perceptual experience and the object of the experience suggests that modifying Searle's proposal regarding perceptual content to include direct causal dependence would furnish the content view with an account of object-immediacy. Specifically, the content theorist can claim that a perceptual experience doesn't represent merely that some object is causing that very experience, but rather that the experience directly causally depends on some object. So, for instance, when I have a visual perceptual experience of the book on the table, the experience represents (in part) that this experience directly causally depends on the book's being on the table. According to the present proposal, then, what is unique about perceptual experiences is that the unique causal relation that such experiences stand in to perceived objects is a

\footnotetext{
${ }^{28}$ When the perceiver is not causally connected to the (approximately) present state of the thing perceived, a non-veridical perceptual experience results.
} 
constituent of the proposition that constitutes a perceptual experience's representational content. ${ }^{29}$ I will call the view that perceptual experiences possess such contents the direct causal content view.

Unlike the representation of causal relations as such, the representation of direct causal dependence would seem to be sufficient for object-immediacy. In particular, the direct causal content view succeeds precisely where Searle's view fails. When I notice the book on the table and consciously think that there is a book on the table, I am aware that this thought about the book is causally mediated by my visual experience of the book. Moreover, I am aware that my thought that the book is on the table is not caused automatically by a causal link between my thought and the present state of the book. So, while I can consciously think that there is a book on the table and that there is a book on the table is causing this very thought, I cannot consciously think that there is a book on the table and this very thought directly causally depends on the book's being on the table. Of course, I can consciously entertain or grasp the latter proposition, but I can't think that this proposition is true. That is, I can't voluntarily adopt the kind of attitude toward this proposition that involves the sort of commitment that is present in belief and perceptual experience and absent from merely grasping or considering some proposition. ${ }^{30}$

If the foregoing is correct, then any commitment-involving propositional attitude that possesses such a content will possess object-immediacy. So, the direct causal content theorist's picture of perceptual experience has a feature that suffices for object-immediacy. And since the notions of a commitment-involving attitude and direct causal dependence can be specified without appealing to the very phenomenology to be explained, this theory's account of object-immediacy is not circular.

In addition, the direct causal content view can also provide an account of objectdistinctness. If Siegel (2006, p. 374) is correct that brute sensations possess some kind of representational content, then one can plausibly claim that what distinguishes the contents of such experiences from those of perceptual experiences is that the former do not represent relations of direct causal dependence. It should be clear, for instance, that when you have an experience of some particular phosphene that your experience does not represent that the phosphene causes the experience without the mediation of any distinct experience or that it is caused automatically by a causal link between the experience and the present state of the phosphene. When you have such an experience the phosphene seems to be merely some aspect of your experience rather than something on which your experience causally depends. ${ }^{31}$ Consequently, we may conclude that any commitment-involving propositional

\footnotetext{
${ }^{29}$ For ease of presentation I'm assuming that perceptual contents are Russellian propositions. However, I believe that the present proposal could be adapted to the view that perceptual contents are Fregean propositions. This proposal is also neutral on the question of whether perceptual contents are general or singular propositions.

30 This notion of commitment is discussed, for instance, by Siegel (2010, pp. 49-50).

31 Siegel (2006, p. 379) denies that the possession of causal contents can be what distinguishes perceptual experiences from brute sensations, but she does not explain how the claim that brute sensations also possess such contents could be defended.
} 
attitude that possesses the sort of content at issue will possess object-distinctness; and, as such, that feature of perceptual experience that the direct causal content theorist claims suffices for object-immediacy also suffices for object-distinctness. ${ }^{32}$

\section{Conclusion}

As we have seen, many philosophers claim that naïve realism has a distinct advantage over the content view accounting for the distinctive phenomenology of perceptual experience-this perceived phenomenological advantage has perhaps even been the principal attraction of the view in contemporary philosophy. However, for the reasons provided above I believe that this claim is false.

First, when we examine the naïve realist account of the phenomenological directness of perceptual experience closely, it appears that the only plausible such account is circular. However, the defender of the content view quite clearly has the resources to provide a very similar, and similarly circular, account of this phenomenology. So, despite what is often assumed, naïve realism has no particular advantage explaining the relevant phenomenology. Once again, this conclusion is important: given that naïve realism has special difficulties accounting for illusion and hallucination, we need good reasons to prefer it to the content view; if naïve realism does not have an advantage explaining the phenomenological directness of perceptual experience, then a crucial source of support for the view is lost.

However, in addition, I hope to have shown that a particular variety of the content view in fact provides a plausible non-circular account of the phenomenological directness of perceptual experience. If so, then there is a powerful phenomenological reason to prefer the direct causal content view to other varieties of the content view, and more importantly, to naïve realism. Since the only plausible account of the phenomenological directness of perceptual experience naïve realism provides is circular, the direct causal content view provides a more satisfying account. Assuming, then, that providing a more satisfying account of the phenomenological directness of perceptual experience than rival theories do is a compelling reason to prefer a particular theory to its rivals, we have a compelling reason to prefer the direct causal content view to naïve realism.

\section{References}

Alston, W. (1999). Back to the theory of appearing. In J. Tomberlin (Ed.), Philosophical perspectives 13: Epistemology (pp. 181-203). Malden, MA: Blackwell.

\footnotetext{
32 A natural objection is that the present view characterizes perceptual contents as implausibly complex or sophisticated. See Millar (forthcoming, Sect. 4.4) for a response.
} 
Block, N. (1996). Mental paint and mental latex. In E. Villanueva (Ed.), Philosophical issues 7: Perception (pp. 19-49). Atascadero, CA: Ridgeview.

Boghossian, P. A., \& Velleman, J. D. (1989). Colour as a secondary quality. Mind, 98, 81-103.

Brewer, B. (2004). Realism and the nature of perceptual experience. In E. Sosa \& E. Villanueva (Eds.), Philosophical issues 14: Epistemology (pp. 61-77). Malden, MA: Blackwell.

Brewer, B. (2011). Perception and its objects. Oxford: Oxford University Press.

Burge, T. (2003). Qualia and intentional content: Reply to block. In M. Hahn \& B. Ramberg (Eds.), Reflections and replies (pp. 405-415). Cambridge, MA: MIT Press.

Byrne, A. (2009). Experience and content. Philosophical Quarterly, 59, 429-451.

Byrne, A., \& Logue, H. (2008). Either/or. In A. Haddock \& F. Macpherson (Eds.), Disjunctivism: Perception, action, knowledge (pp. 57-94). Oxford: Oxford University Press.

Campbell, J. (2002). Reference and consciousness. Oxford: Clarendon Press.

Chalmers, D. (2004). The representational character of experience. In B. Leiter (Ed.), The future for philosophy (pp. 153-181). Oxford: Clarendon Press.

Crane, T. (2006). Is there a perceptual relation? In T. S. Gendler \& J. Hawthorne (Eds.), Perceptual experience (pp. 126-146). Oxford: Clarendon Press.

Fish, W. (2009). Perception, hallucination, and illusion. Oxford: Oxford University Press.

Frey, C. (2013). Phenomenal presence. In U. Kriegel (Ed.), Phenomenal intentionality (pp. 71-92). Oxford: Oxford University Press.

Hellie, B. (2005). Noise and perceptual indiscriminability. Mind, 114, 481-508.

Hellie, B. (2006). Beyond phenomenal naiveté. Philosophers' Imprint, 6(2), 1-24.

Hellie, B. (2007). Factive phenomenal characters. In J. Hawthorne (Ed.), Philosophical perspectives 21: Philosophy of mind (pp. 259-306). Malden, MA: Blackwell.

Husserl, E. (1900/1970). Logical investigations (J. N. Findlay, Trans.). London: Routledge and Kegan Paul.

Jeshion, R. (2010). Singular thought: Acquaintance, semantic instrumentalism, and cognitivism. In R. Jeshion (Ed.), New essays on singular thought (pp. 105-140). Oxford: Oxford University Press.

Johnston, M. (2004). The obscure object of hallucination. Philosophical Studies, 120, 113-183.

Kennedy, M. (2009). Heirs of nothing: The implications of transparency. Philosophy and Phenomenological Research, 79, 574-604.

Langsam, H. (1997). The theory of appearing defended. Philosophical Studies, 87, 33-59.

Martin, M. G. F. (1997). The reality of appearances. In M. Sainsbury (Ed.), Thought and ontology (pp. 81-106). Milano: Franco Angeli.

Martin, M. G. F. (2002). The transparency of experience. Mind and Language, 17, 376-425.

Martin, M. G. F. (2004). The limits of self-awareness. Philosophical Studies, 120, 37-89.

Millar, B. (forthcoming). The phenomenological problem of perception. Philosophy and Phenomenological Research.

Nudds, M. (2009). Recent work in perception: Naïve realism and its opponents. Analysis, 69, 334-346.

Pace, M. (2007). Blurred vision and the transparency of experience. Pacific Philosophical Quarterly, 88, $328-354$.

Pautz, A. (2007). Intentionalism and perceptual presence. In J. Hawthorne (Ed.), Philosophical perspectives 21: Philosophy of mind (pp. 495-541). Malden, MA: Blackwell.

Pautz, A. (2009). What are the contents of experiences? Philosophical Quarterly, 59, 483-507.

Pautz, A. (2010). Why explain visual experience in terms of content? In B. Nanay (Ed.), Perceiving the world (pp. 254-309). Oxford: Oxford University Press.

Schellenberg, S. (2011). Ontological minimalism about phenomenology. Philosophy and Phenomenological Research, 83, 1-40.

Searle, J. (1983). Intentionality. Cambridge, MA: Cambridge University Press.

Searle, J. (1991). Response: Perception and the satisfactions of intentionality. In E. Lepore \& R. Van Gulick (Eds.), John Searle and his critics (pp. 181-192). Cambridge, MA: Blackwell.

Siegel, S. (2006). Subject and object in the contents of visual experience. Philosophical Review, 115, $355-388$.

Siegel, S. (2010). The contents of visual experience. Oxford: Oxford University Press.

Smith, A. D. (2002). The problem of perception. Cambridge, MA: Harvard University Press.

Smith, A. D. (2008). Translucent experiences. Philosophical Studies, 140, 197-212.

Speaks, J. (2009). Transparency, intentionalism, and the nature of perceptual content. Philosophy and Phenomenological Research, 79, 539-573. 
Spener, M. (2012). Mind-independence and visual phenomenology. In D. Smithies \& D. Stoljar (Eds.), Introspection and consciousness (pp. 381-403). Oxford: Oxford University Press.

Strawson, P. F. (1979). Perception and its objects. In G. F. MacDonald (Ed.), Perception and identity (pp. 41-60). Ithaca, NY: Cornell University Press.

Sturgeon, S. (2000). Matters of mind. London: Routledge.

Thau, M. (2002). Consciousness and cognition. Oxford: Oxford University Press.

Williamson, T. (2000). Knowledge and its limits. Oxford: Oxford University Press. 